\title{
A Common Molecular Basis for Exogenous and Endogenous Cannabinoid Potentiation of Glycine Receptors
}

\author{
Wei Xiong, ${ }^{1}$ Xiongwu Wu, ${ }^{2}$ David M. Lovinger, ${ }^{1}$ and Li Zhang ${ }^{1}$ \\ ${ }^{1}$ Laboratory for Integrative Neuroscience, National Institute on Alcohol Abuse and Alcoholism, and ${ }^{2}$ Laboratory of Computational Biology, National Heart, \\ Lung, and Blood Institute, National Institutes of Health, Bethesda, Maryland 20892
}

\begin{abstract}
Both exogenous and endogenous cannabinoids can allosterically modulate glycine receptors (GlyRs). However, little is known about the molecular basis of cannabinoid-GlyR interactions. Here we report that sustained incubation with the endocannabinoid anandamide (AEA) substantially increased the amplitude of glycine-activated current in both rat cultured spinal neurons and in HEK-293 cells expressing human $\alpha 1$, rat $\alpha 2$ and $\alpha 3$ GlyRs. While the $\alpha 1$ and $\alpha 3$ subunits were highly sensitive to AEA-induced potentiation, the $\alpha 2$ subunit was relatively insensitive to AEA. Switching a serine at 296 and 307 in the TM3 (transmembrane domain 3) of the $\alpha 1$ and $\alpha 3$ subunits with an alanine (A) at the equivalent position in the $\alpha 2$ subunit converted the $\alpha 1 / \alpha 3$ AEA-sensitive receptors to sensitivity resembling that of $\alpha 2$. The S296 residue is also critical for exogenous cannabinoid-induced potentiation of $I_{\text {Gly }}$. The magnitude of AEA potentiation decreased with removal of either the hydroxyl or oxygen groups on AEA. While desoxy-AEA was significantly less efficacious in potentiating $I_{\mathrm{Gly}}$, desoxy-AEA inhibited potentiation produced by both $\Delta^{9}$-tetrahydrocannabinol (THC), a major psychoactive component of marijuana, and AEA. Similarly, didesoxy-THC, a modified THC with removal of both hydroxyl/oxygen groups, did not affect $I_{\text {Gly }}$ when applied alone but inhibited the potentiation of $I_{\mathrm{Gly}}$ induced by AEA and THC. These findings suggest that exogenous and endogenous cannabinoids potentiate GlyRs via a hydrogen bonding-like interaction. Such a specific interaction likely stems from a common molecular basis involving the S296 residue in the TM 3 of the $\alpha 1$ and $\alpha 3$ subunits.
\end{abstract}

\section{Introduction}

Emerging evidence has suggested that glycine receptors (GlyRs) are an important target for actions of exogenous and endogenous cannabinoids in the CNS (Zhang and Xiong, 2009). A number of recent studies have shown that cannabinoids can potentiate GlyR-mediated responses in various neurons and in cells expressing recombinant GlyRs via $\mathrm{CB}_{1}$ and $\mathrm{CB}_{2}$ independent mechanisms (Hejazi et al., 2006; Yang et al., 2008; Ahrens et al., 2009; Delaney et al., 2010; Xiong et al., 2011; Yevenes and Zeilhofer, 2011a). In addition to modulating GlyRs, both exogenous and endogenous cannabinoids have been shown to allosterically modulate all other members of the Cys-loop ligand-gated ion channels (LGICs) including serotonin type $3 \mathrm{~A}\left(5-\mathrm{HT}_{3 \mathrm{~A}}\right)$, neuronal nicotinic acetylcholine (nACh) and $\mathrm{GABA}_{\mathrm{A}}$ receptors (Fan, 1995; Barann et al., 2002; Oz et al., 2004; Hejazi et al., 2006; Xiong et al., 2008; Sigel et al., 2011). There is strong evidence to suggest that some of the cannabinoid-induced behavioral effects are independent of $\mathrm{CB}_{1}$ receptors. The endocannabinoid anandamide

Received Dec. 20, 2011; revised Feb. 9, 2012; accepted Feb. 25, 2012.

Author contributions:W.X. and L.Z. designed research;W.X., X.W., and L.Z. performed research;W.X., D.M.L., and L.Z. analyzed data; W.X., D.M.L., and L.Z. wrote the paper.

This work was supported by funds from the intramural program of the National Institute on Alcohol Abuse and Alcoholism. We thank Drs. Kejun Cheng and Fuying Li for providing modified cannabinoids (didesoxy-THC, desoxy$A E A$, and dehydroxyl-AEA). We also thank Dr. Zhifeng Zhou for technical assistance with DNA sequencing.

Correspondence should be addressed to Li Zhang, Laboratory for Integrative Neuroscience, National Institute on Alcohol Abuse and Alcoholism, National Institutes of Health, 5625 Fishers Lane, Bethesda, MD 20892. E-mail: Izhang@mail.nih.gov.

DOI:10.1523/JNEUROSCI.6347-11.2012

Copyright $\odot 2012$ the authors $\quad 0270-6474 / 12 / 325200-09 \$ 15.00 / 0$
(AEA) stimulates GTP $\gamma \mathrm{S}$ binding in brain membranes isolated from mice lacking $\mathrm{CB}_{1}$ receptors, and this effect is not altered by $\mathrm{CB}_{1}$ and $\mathrm{CB}_{2}$ antagonists (Di Marzo et al., 2000). $\Delta^{9}$ tetrahydrocannabinol (THC), the principle psychoactive component of marijuana, and AEA-induced analgesic effects in the tail flick test (for THC) and hot-plate test (for AEA) remain intact in mice with depleted $\mathrm{CB}_{1}$ receptors $\left(\mathrm{CB}_{1}^{-/-}\right)$(Zimmer et al., 1999; Di Marzo et al., 2000) or both $\mathrm{CB}_{1}$ and $\mathrm{CB}_{2}$ receptors (Rácz et al., 2008). A recent study from our laboratory has suggested that exogenous and synthetic cannabinoid potentiation of GlyRs contributes to psychoactive and nonpsychoactive cannabinoidinduced analgesic effect in the tail flick reflex in mice (Xiong et al., 2011).

The GlyRs are involved in several physiological and pathological processes including neuromotor activity, antinociception, muscle relaxation, anxiety and reward mechanisms (Lynch, 2009). The GlyRs are formed as pentameric homomeric chloride channels of $\alpha 1, \alpha 2, \alpha 3$ and $\alpha 4$ subunits or as $\alpha \beta$ heteromeric functional channels (Lynch, 2004). Each GlyR subunit is composed of an extracellular domain, four transmembrane domains (TMs) and a large cytoplasmic domain between TM3 and TM4. There is strong evidence showing that distinct sites located in these domains mediate functional modulation of GlyRs by different allosteric modulators (Lobo and Harris, 2005; Harris et al., 2008; Foadi et al., 2010; Xiong et al., 2011; Yevenes and Zeilhofer, 2011a). A recent study has revealed a serine at position 296 in the TM3 of GlyR as a distinct site to critically regulate THC-induced potentiation of GlyR (Xiong et al., 2011). However, little is known about the molecular mechanisms underlying endocannabinoid 


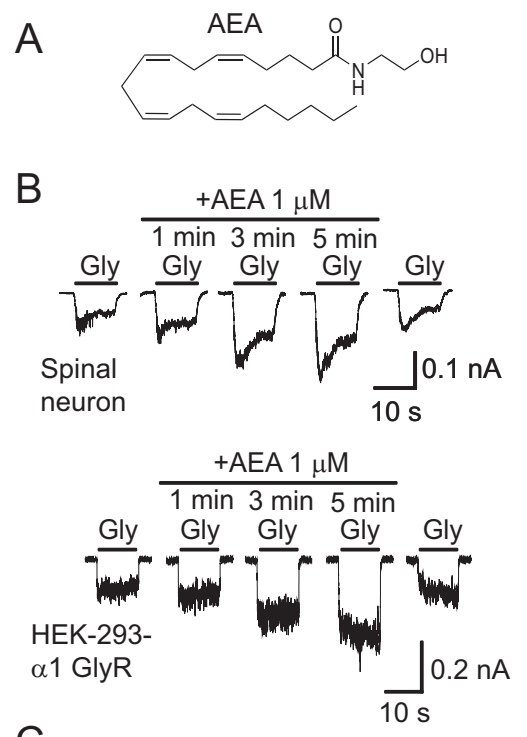

C

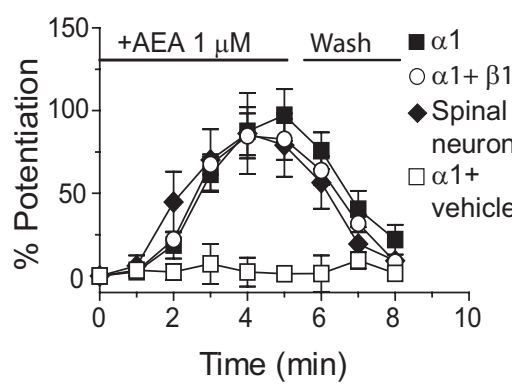

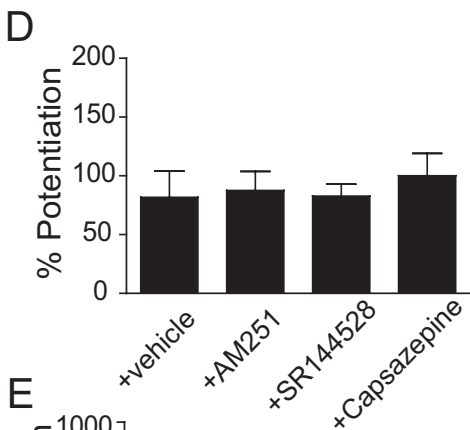
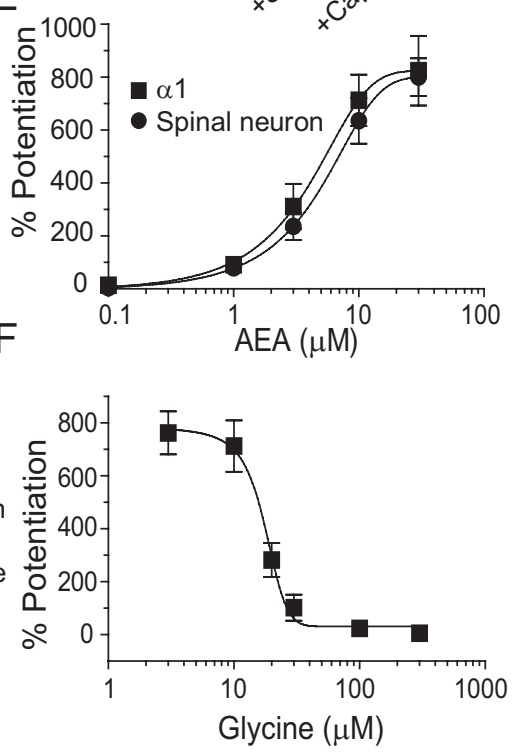

Figure 1. AEA potentiation of $I_{\text {Gly }}$ in cultured spinal neurons and HEK-293 cells expressing $\alpha 1$ and $\beta 1$ GlyRs. $\boldsymbol{A}$, Chemical structure of AEA. B, Current traces showing $I_{\text {Gly }}$ activated by $\mathrm{EC}_{2}$ concentrations of $\mathrm{Gly}(5-10 \mu \mathrm{m})$ before, during and after a $5 \mathrm{~min}$ continuous incubation with AEA in cultured spinal neurons (top) and in HEK-293 cells expressing the $\alpha 1$ GlyR subunits (bottom).C, Time courses of average percentage potentiation induced by $1 \mu \mathrm{m}$ AEA during a $5 \mathrm{~min}$ period of continuous incubation. The solid bar indicates AEA application time in cultured neurons (solid diagonals) and in HEK-293 cells expressing $\alpha 1$ GlyRs (solid squares) and $\alpha 1 \beta 1$ GlyRs (open circles). Each point represents mean \pm SE of at least 6 cells. D, Effects of AM251, SR144528 and capsazepine on AEA potentiation ( $n=5-7)$. $E$, The concentration-response curve of the AEA-induced potentiation in cultured neurons $(n=$ 6) and HEK-293 cells expressing the $\alpha 1$ subunit $(n=6)$. $\boldsymbol{F}$, Agonist concentration dependence of AEA-induced potentiation of $I_{\text {Gly }}$ in HEK-293 cells expressing the $\alpha 1$ subunits $(n=5)$. The error bars that are not visible are smaller than the size of symbols.

AEA potentiation of GlyRs. Here we report that the $\alpha 1, \alpha 2$ and $\alpha 3$ GlyR subunits are differentially sensitive to the AEA-induced potentiation of $I_{\mathrm{Gly}}$. The $\mathrm{S} 296$ residue already implicated in THC potentiation of $\alpha 1$ GlyR function contributes to the differential sensitivity of different GlyR subunits to sustained AEA application. We have also provided evidence to suggest that exogenous and endogenous cannabinoids interact with GlyRs through a common molecular basis.

\section{Materials and Methods}

\section{Cultured spinal neurons}

Animals were treated and handled according to NIH guidelines. Postnatal day 0 rats of either sex were killed by cervical dislocation. The spinal cords were removed from three to five rats. The tissue, which was chopped into small pieces, was incubated with $5 \mathrm{ml}$ of papain solution (Worthington, $20 \mathrm{U} / \mathrm{ml}$ ) at $37^{\circ} \mathrm{C}$ for $40 \mathrm{~min}$. The tissue was washed and triturated through a 9 inch glass Pasteur pipette with the tip fire polished to an opening of $0.7-0.9 \mathrm{~mm}$ diameter. The cell suspension was centrifuged at $120 \times g$ for $5 \mathrm{~min}$ and the supernatants were discarded. Spinal neurons were resuspended and plated, at a concentration of 300,000 cells $/ \mathrm{ml}$, into $35 \mathrm{~mm}$ tissue culture dishes coated with poly-D-lysine $(0.1$ $\mathrm{mg} / \mathrm{ml}$ ). The neuronal feeding medium consisted of $90 \%$ minimum essential medium, $10 \%$ heat-inactivated fetal bovine serum and a mixture of nutrient supplements (Invitrogen). New medium was added every $3 \mathrm{~d}$. Cells were cultured for at least $10 \mathrm{~d}$ and washed with normal external solution (see below) for $30 \mathrm{~min}$ before starting the electrophysiological experiments.

HEK-293 cell transfection and electrophysiological recording

HEK-293 cells were cultured as described previously (Hu et al., 2006). The plasmid cDNAs coding for the wild-type and mutant GlyR subunits and human $5-\mathrm{HT}_{3 \mathrm{~A}}$ receptors (5$\mathrm{HT}_{3 \mathrm{~A}} \mathrm{Rs}$ ) were transfected using the SuperFect Transfection Kit (Qiagen). Electrophysiological recordings were performed $2 \mathrm{~d}$ after transfection. HEK-293 cells were treated with $0.25 \%$ (w/v) Trypsin and 0.53 mм EDTA $2 \mathrm{~h}$ before recording. The HEK-293 cells were lifted and continuously superfused with a solution containing (in mM): $140 \mathrm{NaCl}, 5 \mathrm{KCl}, 1.8 \mathrm{CaCl}_{2}$, $1.2 \mathrm{MgCl}_{2}, 5$ glucose, and 10 HEPES ( $\mathrm{pH} 7.4$ with $\mathrm{NaOH} ; \sim 340 \mathrm{mOsm}$ with sucrose). Patch pipettes $(3-5 \mathrm{M} \Omega$ ) were filled with the intracellular solution that contained the following (in $\mathrm{mm}): 120 \mathrm{CsCl}, 4 \mathrm{MgCl}_{2}, 10$ EGTA, 10 HEPES, $0.5 \mathrm{Na}-\mathrm{GTP}$, and $2 \mathrm{Mg}$-ATP (pH 7.2 with $\mathrm{CsOH}, \sim 280 \mathrm{mOsm})$. Membrane currents were recorded in the whole-cell configuration using an Axopatch 200B amplifier (Axon) at $20-22^{\circ} \mathrm{C}$. Cells were held at $-60 \mathrm{mV}$ unless otherwise indicated. Data were acquired using pClamp 9.2 software (Molecular Devices). Data were filtered at $1 \mathrm{kHz}$ and digitized at 2 $\mathrm{kHz}$. Bath solutions were applied through 3 barrel square glass tubing (Warner Instrument) with a tip diameter of $\sim 700 \mu \mathrm{m}$. Drugs were applied using a Warner fast-step steppermotor driven system. The solution exchange time constants were $\sim 4 \mathrm{~ms}$ for an open pipette tip and 4-12 ms for whole-cell recording.

\section{Site-directed mutagenesis}

Point-mutations of the human $\alpha 1$ GlyR, rat $\alpha 2$ and $\alpha 3$ GlyR subunits, and human $5-\mathrm{HT}_{3 \mathrm{~A}} \mathrm{R}$ were introduced using a QuikChange SiteDirected Mutagenesis Kit (Stratagene). The authenticity of the DNA sequence through the mutation sites was confirmed by doublestranded DNA sequencing using a CEQ 8000 Genetic Analysis System (Beckman Coulter, Inc).

\section{Molecular modeling and simulations}

$\alpha 1$ GlyR and 5-HT ${ }_{3 \mathrm{~A}} \mathrm{R}$ were modeled with SWISS-MODEL (Guex and Peitsch, 1997; Schwede et al., 2003; Arnold et al., 2006), using a homologous structure (PDB code: $3 \mathrm{ehz}$, chain A) as a template. Five $\alpha 1$ GlyR or $5-\mathrm{HT}_{3 \mathrm{~A}} \mathrm{R}$ chains were superimposed on the five chains of the nicotinic acetylcholine receptor (PDB code: $2 \mathrm{bg} 9$ ) to create a pentamer conformation. CHARMM (Brooks et al., 1983, 2009) package was used to perform minimization and simulation. For efficient simulation, the N-terminal extracellular domains (1-252) were removed. THC and AEA molecules were placed in the membrane region near TM3. The C-terminal transmembrane helix bound together with the AEA molecules was minimized and simulated for $2 \mathrm{~ns}$ with the self-guided Langevin dynamics method (Wu and Brooks, 2003, 2011) to search for stable conformations.

\section{Drugs}

Most chemicals including glycine (Gly) were from Sigma. Solutions were prepared on the day of the experiment. Agonists and other compounds were diluted either directly in the bath solution or dissolved in ethanol before further dilution. The maximal concentration of ethanol in the bath solution was $<8 \mathrm{~mm}$, which, when applied alone, did not affect either $I_{\mathrm{Gly}}$ or AEA-induced potentiation of $I_{\mathrm{Gly}}$. The maximal concentra- 
tion of THC and AEA used was $30 \mu \mathrm{m}$ because the compounds were difficult to keep in solution at concentrations $>30 \mu \mathrm{M}$.

\section{Chemical synthesis}

Desoxyanandamide. $\mathrm{LiAlH}_{4}$ of $0.14 \mathrm{ml}$ at $1 \mathrm{M}$ in THF, $0.14 \mathrm{ml}$ ) was added dropwise to $5 \mathrm{ml}$ of anandamide $(25 \mathrm{mg}, 0.072 \mathrm{mmol}$ ) in anhydrous THF under Argon at $0^{\circ} \mathrm{C}$. The resulting solution was warmed up to room temperature for $1 \mathrm{~h}$ and heated to reflux overnight. The reaction mixture was cooled to $0^{\circ} \mathrm{C}$ again and a solution of Rochelle salt was added cautiously. After being stirred for $1 \mathrm{~h}$, the mixture was extracted with $\mathrm{CH}_{2} \mathrm{Cl}_{2}$ $(3 \times 20 \mathrm{ml})$. The combined extracts were washed with brine and dried over anhydrous $\mathrm{Na}_{2} \mathrm{SO}_{4}$. After filtration and concentration, the crude product was purified by flash chromatography $\left(\mathrm{CHCl}_{3}: \mathrm{MeOH}\right.$ : $\left.\mathrm{NH}_{4} \mathrm{OH}=90: 9: 1\right)$ to afford desoxyanandamide (desoxy-AEA) $(6.1 \mathrm{mg}$, $25.4 \%)$ as clear oil. ESI-MS $334.3\left(\mathrm{M}^{+}+1\right)$; $\mathrm{HRMS}\left(\mathrm{ES}^{+}\right)$calculated for $\mathrm{C}_{22} \mathrm{H}_{40} \mathrm{NO}$, 334.3110; found, 334.3100 .

Dehydroxylanandamide. Arachidonic acid of $5 \mathrm{ml}(31 \mathrm{mg}, 0.1$ mmol) in $\mathrm{CH}_{2} \mathrm{Cl}_{2}$ was added to a solution containing ethylamine in THF $(2 \mathrm{M}, 0.1 \mathrm{ml}), \mathrm{Et}_{3} \mathrm{~N}(0.3 \mathrm{mmol}, 42 \mu \mathrm{l})$ and 1-ethyl-3-(3dimethylaminopropyl)carbodiimide hydrochloride $(0.2 \mathrm{mmol}, 38 \mathrm{mg})$ successively under argon at $0^{\circ} \mathrm{C}$. The reaction mixture was stirred at room temperature overnight and then diluted with $\mathrm{CH}_{2} \mathrm{Cl}_{2}(20 \mathrm{ml})$. The diluted mixture was washed successively with $2 \mathrm{M} \mathrm{HCl}(10 \mathrm{ml})$ and water. The product was saturated with $\mathrm{NaHCO}_{3}$ and brine, and it was then dried over anhydrous $\mathrm{Na}_{2} \mathrm{OS}_{4}$. After filtration and concentration, the crude product was purified by flash chromatography $\left(\mathrm{CHCl}_{3}: \mathrm{MeOH}\right.$ : $\mathrm{NH}_{4} \mathrm{OH}=98: 1.9: 0.1$ ) to give dehydroxylanandamide (dehydroxyl-AEA; $23.7 \mathrm{mg}, 71.6 \%)$ as clear oil. ${ }^{1} \mathrm{H} \mathrm{NMR}\left(\mathrm{CDCl}_{3}, 400 \mathrm{MHz}\right) \delta 5.36(m, 8 \mathrm{H})$, $3.27(m, 2 \mathrm{H}), 2.82(m, 6 \mathrm{H}), 2.10(m, 6 \mathrm{H}), 1.71(m, 2 \mathrm{H}), 1.31(m, 6 \mathrm{H}), 1.13$ $(t, J=7.2 \mathrm{~Hz}, 3 \mathrm{H}), 0.88(t, J=6.4 \mathrm{~Hz}, 3 \mathrm{H}) ;{ }^{13} \mathrm{C} \mathrm{NMR}\left(\mathrm{CDCl}_{3}, 100 \mathrm{MHz}\right)$ $\delta 172.6,130.5,129.2,128.7,128.6,128.23,128.20,127.9,127.5,36.1,34.3$, $31.5,29.3,27.2,26.7,25.6,25.5,22.6,14.9,14.0$; ESI-MS $332.3\left(\mathrm{M}^{+}+1\right)$; HRMS (ES ${ }^{+}$) calculated for $\mathrm{C}_{22} \mathrm{H}_{38} \mathrm{NO}$, 332.2953; found, 332.2960.

Didesoxy-THC. Didesoxy-THC was synthesized as described previously (Xiong et al., 2011).

\section{Data analysis}

Statistical analysis of concentration-response data was performed using the nonlinear curve-fitting program (Prism 5.0). Data were fit using the Hill equation $I / I_{\max }=$ Bottom $+($ Top - Bottom $) /(1+$ $10^{\left(\operatorname{LogEC}_{50}-\log [\text { Agonist }]\right){ }^{*} \text { Hill }}{ }^{\text {Slope })}$ where $I$ is the current amplitude activated by a given concentration of agonist ([Agonist]), $I_{\max }$ is the maximum response of the cell, and $\mathrm{EC}_{50}$ is the concentration eliciting a half-maximal response. Data were statistically compared by the unpaired $t$ test, or ANOVA, as noted. Average values are expressed as mean \pm SE.

\section{Results}

\section{AEA potentiation of native and recombinant GlyRs}

While AEA did not trigger detectable current even at high concentrations $(>30 \mu \mathrm{M}), \mathrm{AEA}$ at $1 \mu \mathrm{M}$ increased the magnitude of currents activated by a $2 \%$ maximal effective $\left(\mathrm{EC}_{2}\right)$ concentration of Gly in cultured spinal neurons and in HEK-293 cells expressing human $\alpha 1$ GlyRs (Fig. $1 B$ ). AEA was always applied after stable $I_{\mathrm{Gly}}$ as basal current was achieved. When AEA was applied continuously with intermittent Gly applications every minute, the potentiation gradually increased over the first few minutes of sustained AEA exposure. The maximal magnitude of potentiation was reached after 5 min of sustained AEA application in both spinal neurons and in HEK-293 cells expressing the $\alpha 1$ homomeric and $\alpha 1 \beta 1$ heteromeric GlyRs (Fig. $1 C$ ). Consistent with a previous study showing that the $\alpha 1$ subunits were abundantly expressed in cultured spinal neurons (Tapia and Aguayo, 1998), the magnitudes of AEA potentiation of $I_{\mathrm{Gly}}$ appeared similar between spinal neurons and HEK-293 cells expressing the $\alpha 1$ subunits. For instance, the average percentage potentiation of $I_{\mathrm{Gly}}$ induced by $1 \mu \mathrm{M}$ AEA was $86 \pm 24 \%(n=6)$ in spinal neurons
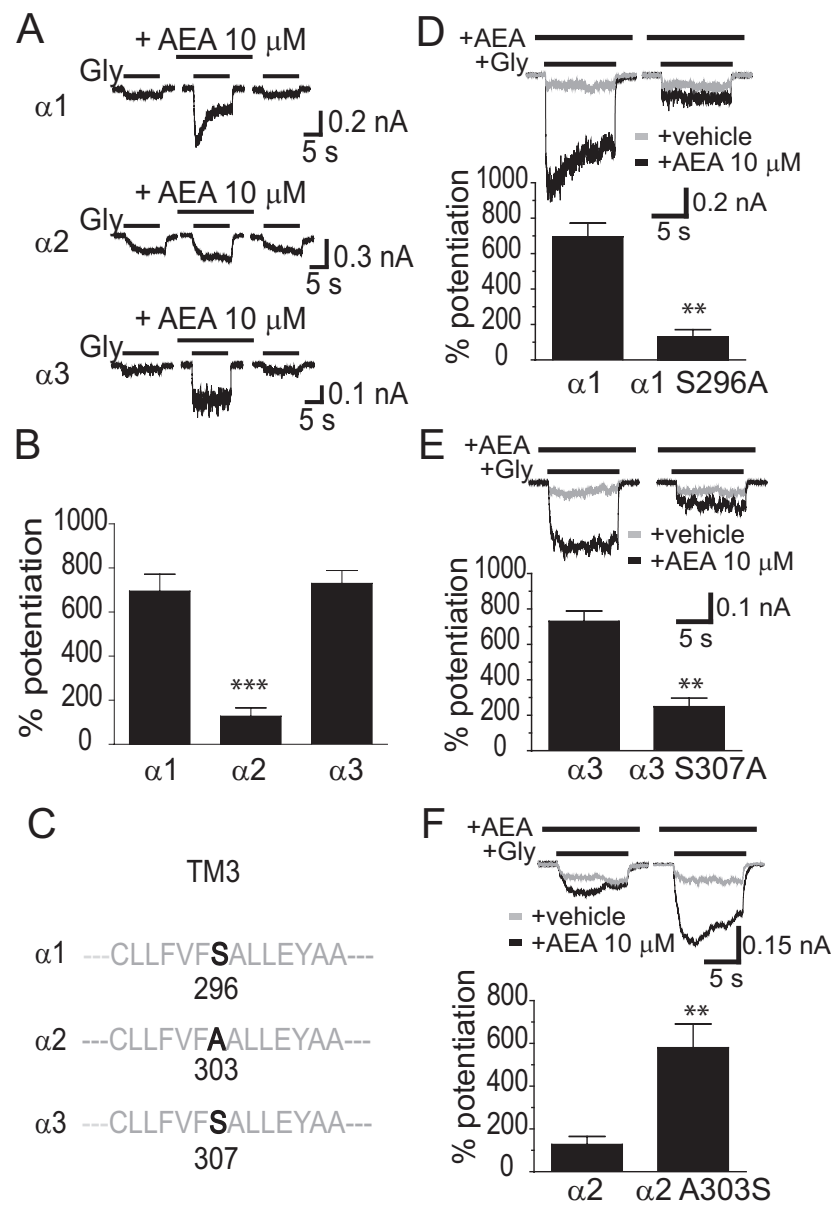

Figure 2. S296 is critical for AEA potentiation of $\alpha 1$ and $\alpha 3$ GlyRs. A, Differential AEA potentiation of $I_{\text {Gly }}$ activated by $\mathrm{EC}_{2}$ concentrations of Gly ( $10 \mu \mathrm{m}$ for the $\alpha 1$ subunit, $20 \mu \mathrm{m}$ for the $\alpha 2$ subunit and $100 \mu \mathrm{m}$ for the $\alpha 3$ subunit) in HEK-293 cells. The AEA (10 $\mu \mathrm{M})$ was applied before agonist, and applied continuously for 5 min with intermittent 10 s Gly + AEA applications as shown in Figure $1 B . B$, Average potentiation by AEA of $I_{\text {Gly }}$ in different HEK-293 cells expressing $\alpha 1, \alpha 2$ or $\alpha 3$ GlyRs $(n=6-7)$. ${ }^{* * *} p<0.001, \alpha 2$ vs $\alpha 1$ or $\alpha 3$, one-way ANOVA followed by Dunnett's post hoc test. C, Amino acid alignment of the TM3 region flanking S296 $(\alpha 1)$ or equivalent residues in the $\alpha 2$ (A303) and $\alpha 3$ (S307) subunits. D, The effect of AEA (10 $\mu \mathrm{M})$ on $I_{\text {Gly }}$ activated by an $\mathrm{EC}_{2}$ concentration of Gly $(10 \mu \mathrm{M})$ in cells expressing the $5296 \mathrm{~A}$ mutant and wild-type $\alpha 1$ GlyRs. $E$, The effects of AEA $(10 \mu \mathrm{m})$ on $I_{\text {Gly }}$ activated by the $\mathrm{EC}_{2}$ concentration of Gly (100 $\mu \mathrm{m})$ in cells expressing the S307A mutant and wild-type $\alpha 3$ GlyRs. $\boldsymbol{F}$, The effects of AEA (10 $\mu \mathrm{m})$ on $I_{\text {Gly }}$ activated by the $\mathrm{EC}_{2}$ concentration of Gly $(20 \mu \mathrm{m})$ in cells expressing the $\mathrm{A} 303 \mathrm{~S}$ mutant and wild-type $\alpha 2 \mathrm{GlyRs.}{ }^{* *} p<0.01$, unpaired $t$ test.

and $97 \pm 16 \%(n=7)$ or $85 \pm 12 \%(n=6)$ in HEK-293 cells expressing the $\alpha 1$ or $\alpha 1 \beta 1$ subunits. These values were significantly higher than the initial values observed after 1 min of AEA exposure, $6 \pm 6 \%$ (neurons) and $3 \pm 1 \%$ (HEK-293 cells) $(p<$ 0.05 , one-way ANOVA followed by Dunnett's test comparing the last response to the response in the first minute).

In addition to activating $\mathrm{CB}_{1}$ and $\mathrm{CB}_{2}$ receptors, $\mathrm{AEA}$ also activates vanilloid receptors in neurons (Pertwee, 2000; Smart et al., 2000; Ross, 2003). To determine whether AEA potentiates $I_{\mathrm{Gly}}$ through activating $\mathrm{CB}_{1}, \mathrm{CB}_{2}$ and vanilloid receptors, we tested the effects of specific antagonists of these receptors on AEAinduced potentiation of $I_{\mathrm{Gly}}$ in cultured spinal neurons (Fig. 1D). Selective antagonists of $\mathrm{CB}_{1}(\mathrm{AM} 251,1 \mu \mathrm{M}), \mathrm{CB}_{2}$ (SR144528, 1 $\mu \mathrm{M}$ ) and vanilloid (capsazepine, $2 \mu \mathrm{M}$ ) receptors did not significantly alter the AEA-induced potentiation of $I_{\mathrm{Gly}}$ in cultured spinal neurons (AM251, $p=0.84$; SR144528, $p=0.97$; Capsazepine, $p=0.56$ compared with vehicle solution using one-way ANOVA 
A 1.2
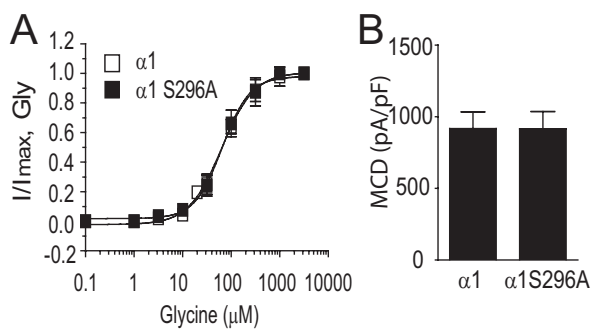

$\mathrm{C}_{1.2}$
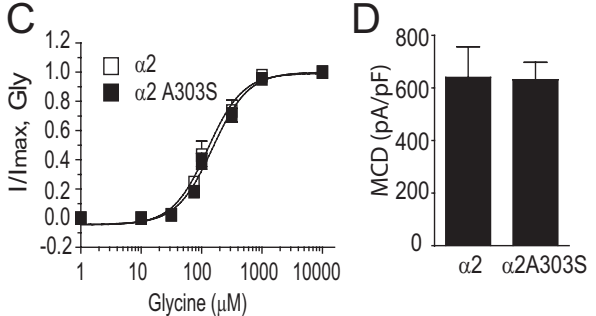

E
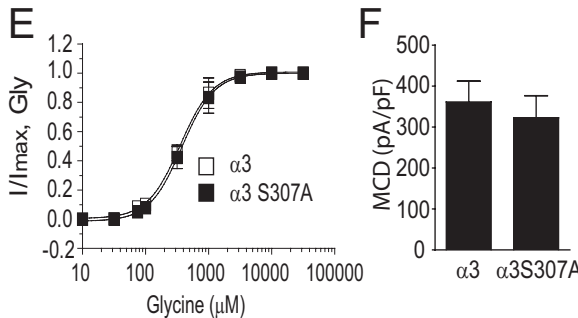

Figure 3. S296 mutation does not affect the basic function of GlyR. $\boldsymbol{A}$, Gly concentrationresponse curves in HEK-293 cells expressing the $2296 \mathrm{~A}$ mutant and wild-type $\alpha 1 \mathrm{GlyRs}$. $\boldsymbol{B}$, The average MCD of $I_{\text {Gly }}$ in HEK-293 cells expressing the $S 296 \mathrm{~A}$ mutant and wild-type $\alpha 1$ GlyRs. $\boldsymbol{C}$, Gly concentration-response curves in HEK-293 cells expressing the A303S mutant and wildtype $\alpha 2$ GlyRs. $D$, The average MCD of $I_{\text {Gly }}$ in HEK-293 cells expressing the A303S mutant and wild-type $\alpha 2$ GlyRs. $\boldsymbol{E}$, Gly concentration-response curves in HEK-293 cells expressing the S307A mutant and wild-type $\alpha 3$ GlyRs. $\boldsymbol{F}$, The average MCD of $I_{\text {Gly }}$ in HEK-293 cells expressing the S307A mutant and wild-type $\alpha 3$ GlyRs. The error bars that are not visible are smaller than the size of symbols. followed by Dunnett's post hoc test), suggesting that AEA potentiation of native GlyRs does not depend on the $\mathrm{CB}_{1}, \mathrm{CB}_{2}$ and vanilloid receptors. AEA enhanced the peak amplitude of $I_{\mathrm{Gly}}$ in a concentration-dependent manner in spinal neurons and HEK293 cells expressing the homomeric GlyR $\alpha 1$ subunit (Fig. 1E). The magnitudes of average percentage potentiation induced by 1 , 3,10 , and $30 \mu \mathrm{M}$ AEA were $91 \pm 9 \%, 311 \pm 86 \%, 712 \pm 96 \%$, and $824 \pm 278 \%$, respectively, in HEK-293 cells, and $79 \pm 19 \%$, $236 \pm 52 \%, 636 \pm 87 \%$ and $800 \pm 71 \%$, respectively, in spinal neurons. The $\mathrm{EC}_{50}$ values for AEA potentiation were $4.2 \pm 1.95$ $\mu \mathrm{M}$ in HEK-293 cells expressing $\alpha 1$ homomeric GlyRs and $5.5 \pm$ $2.0 \mu \mathrm{M}$ in spinal neurons. These values are not significantly different from one another ( $p=0.85$, unpaired $t$ test, $n=5-7)$. AEA potentiation depended on the Gly concentration (Fig. $1 F$ ). With increasing Gly concentrations, the AEA potentiation was decreased. For example, the magnitude of average percentage potentiation induced by $10 \mu \mathrm{M}$ AEA was $712 \pm 96 \%$ in the presence of Gly at $10 \mu \mathrm{M}$ in HEK-293 cells expressing the $\alpha 1$ subunit, while the magnitude of AEA potentiation was $102 \pm 49 \%$ or $24 \pm 6 \%$ when Gly concentrations were increased up to 30 and $100 \mu \mathrm{M}$.

\section{S296: essential for AEA potentiation of the $\alpha 1$ and $\alpha 3$ subunit-containing GlyRs}

Next we asked whether or not three distinct $\alpha$ subunits of GlyRs are differentially sensitive to AEA-induced potentiation. We first determined the $\mathrm{EC}_{50}$ values from the Gly concentration-response curves in HEK-293 cells transfected with $\alpha 1 \alpha 2$ or $\alpha 3$ subunits of GlyR. The $\mathrm{EC}_{50}$ values for Gly were $64 \pm 13 \mu \mathrm{M}$ for the $\alpha 1$ subunit, $128 \pm 10 \mu \mathrm{M}$ for the $\alpha 2$ subunit and $354 \pm 29 \mu \mathrm{M}$ for the $\alpha 3$ subunit. These values were significantly different from one another $(p<0.05$, one-way ANOVA with Dunnett's post hoc test against $\alpha 1, n=6-11$ ). We then examined the effect of AEA on $I_{\text {Gly }}$ activated by $\mathrm{EC}_{2}$ concentrations of Gly in HEK-293 cells expressing each subtype of GlyRs. While the $\alpha 1$ and $\alpha 3$ GlyR subunits appeared to be equally sensitive to AEA-induced potentiation, the $\alpha 2$ GlyR subunits were less sensitive to AEA when expressed in HEK-293 cells (Fig. 2A). The magnitudes of average percentage potentiation induced by $10 \mu \mathrm{M}$ AEA were $695 \pm 76 \%$ and $730 \pm 58 \%$ in cells expressing the $\alpha 1$ and $\alpha 3$ subunits. In contrast, the magnitude of AEA enhancement of receptors containing the $\alpha 2$ subunit ( $127 \pm 37 \%$ ) was significantly lower than that of receptors containing the $\alpha 1$ and $\alpha 3$ subunits ( $p<$ 0.001 compared with $\alpha 1$ or $\alpha 3$, one-way ANOVA with Dunnett's post hoc test, $n=6$ ) (Fig. 2B).

A recent study from our laboratory has suggested that the S296 residue of the $\alpha 1$ and the $\mathrm{S} 307$ of the $\alpha 3$ GlyRs are critical for the THC-induced potentiation of $I_{\text {Gly }}$ (Xiong et al., 2011). We next tested whether the S296/S307 residue is also critical for differential AEA sensitivity of GlyR subunits. The serine (S) at 296 and 307 in the TM3 is conserved between the $\alpha 1$ and $\alpha 3$ subunits, respectively. In contrast, the equivalent residue at 303 of the $\alpha 2$ subunit is Alanine (A), which is the only residue throughout the entire $4 \mathrm{TMs}$ of the $\alpha 2$ subunit that differs from a corresponding residue identical between the $\alpha 1$ (S296) and $\alpha 3$ (S307) subunits (Fig.
Figure 4. Comparison between sustained and simultaneous application of AEA-induced potentiation of GlyRs. A, Potentiation of $I_{\text {Gly }}$ induced by 5 min sustained incubation of THC $(1 \mu \mathrm{m}) / A E A(10 \mu \mathrm{m})$ in HEK-293 cells expressing $\alpha 1, \alpha 2$ and $\alpha 3$ GlyRs. $B_{\text {, }}$ Potentiation of $I_{\text {Gly }}$ induced by simultaneous application of THC $(1 \mu \mathrm{M}) / A E A(10 \mu \mathrm{M})$ in HEK-293 cells expressing $\alpha 1, \alpha 2$ and $\alpha 3$ GlyRs. C, Current trace showing potentiation of $I_{\text {Gly }}$ induced by simultaneous application of AEA or 5 min sustained incubation of 10 $\mu \mathrm{m}$ AEA in HEK-293 cells expressing the S296A mutant and wild-type $\alpha 1 \mathrm{GlyRs}$. The solid bars on the top of traces indicate the time of drug application. D, Quantification of data in experiments shown in $C .{ }^{* *} p<0.001$, unpaired $t$ test. Note that the S296A mutation completely abolished the additional potentiation of $I_{G l y}$ induced by sustained AEA incubation but not by simultaneously coapplied AEA. E, Amino acid alignment of the TM2 region flanking G254 ( $\alpha 1)$ or equivalent residues in the $\alpha 2$ and $\alpha 3$ subunits. $\boldsymbol{F}$, The average percentage potentiation induced by sustained AEA application in HEK-293 cells expressing the G254A mutant and wild-type $\alpha 1$ GlyRs. 
$2 C)$. The S296A mutation in the $\alpha 1$ subunit significantly reduced the magnitude of AEA-induced potentiation from $695 \pm$ $77 \%$ to $131 \pm 41 \%$ (Fig. $2 D, p<0.01, n=$ 7 , unpaired $t$ test). Similarly, The S307A mutation in the $\alpha 3$ subunit also significantly reduced AEA potentiation from $731 \pm 58 \%$ to $249 \pm 48 \%$ (Fig. $2 E, p<$ $0.01, n=6$, unpaired $t$ test). Conversely, substitution of the corresponding residue, A303, of the $\alpha 2$ subunit with serine significantly increased the magnitude of AEAinduced potentiation from $127 \pm 37 \%$ to $580 \pm 110 \%$ (Fig. $2 F, p<0.01, n=6$, unpaired $t$ test). The S296A mutation in the $\alpha 1$ subunit did not significantly affect the Gly $\mathrm{EC}_{50}$ value (Fig. $3 A, 64 \pm 13 \mu \mathrm{M}$ vs $66 \pm 7 \mu \mathrm{M}, p=0.67, n=6$, unpaired $t$ test) and maximal current density (MCD) induced by a maximally efficacious Gly concentration (3 mM) (Fig. 3B, $912 \pm 153$ $\mathrm{pA} / \mathrm{pF}$ vs $906 \pm 147 \mathrm{pA} / \mathrm{pF}, p=0.67, n=$ 6 , unpaired $t$ test). Similarly, neither the A303S mutation of $\alpha 2$ GlyR nor the S307A mutation of $\alpha 3$ GlyR significantly changed the Gly $\mathrm{EC}_{50}$ value and MCD (Fig. 3C-F). We also examined the inhibition of $I_{\mathrm{Gly}}$ by strychnine, a selective glycine receptor antagonist, in cells expressing the S296A mutant and WT $\alpha 1$ receptors. The S296A mutation in the $\alpha 1$ subunit did not significantly affect the strychnine (100 nM)-induced inhibiting effect on $I_{\mathrm{Gly}}$ activated by Gly at an $\mathrm{EC}_{50}$ concentration $(78 \pm 9 \%$ vs $81 \pm 13 \%, n=$ $7, p>0.2)$.

\section{S296 selectively contributes to sustained AEA} application-induced potentiation

The maximal magnitude of AEA potentiation of GlyRs reported here was significantly higher than what we and others described in previous studies in which AEA was simultaneously coapplied with agonists (Hejazi et al., 2006; Ahrens et al., 2009; Yevenes and Zeilhofer, 2011a). One possibility that might account for this discrepancy is that distinct molecular processes are involved in AEA potentiation of GlyRs with and without sustained AEA incubation. To test this hypothesis, we first compared the potentiation of three GlyR subunits induced by sustained AEA application and simultaneous AEA application. Unlike the result obtained from sustained THC and AEA incubation (Fig. 4A), there was no significant difference in either simultaneous THC or simultaneous AEAinduced potentiation of the $\alpha 1, \alpha 2$ and $\alpha 3$ subunits expressed in HEK-293 cells (Fig. $4 B, p>0.2$ ). Next we compared the role of the S296A mutation in both sustained and simultaneous AEA incubation-induced potentiation of the $\alpha 1$ subunit. While the S296A mutation significantly inhibited AEA potentiation after 5 min sustained incubation $(695 \pm 77 \%$ vs $131 \pm 41 \%, p<0.001$, $n=5-6$, unpaired $t$ test), the S296A mutant and WT receptors did not significantly differ in their sensitivity to AEA $(10 \mu \mathrm{M})$ induced potentiation when simultaneously applied only with Gly (Fig. $4 C, D, 108 \pm 15 \%$ vs $99 \pm 20 \%$ ). A very recent study has

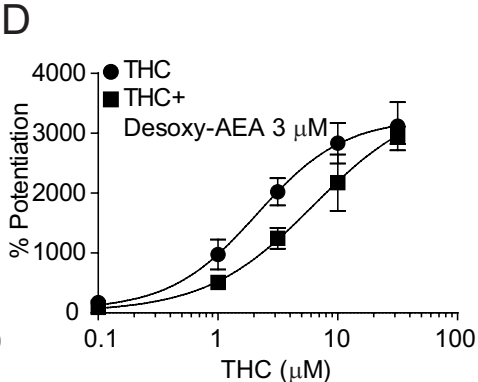

E
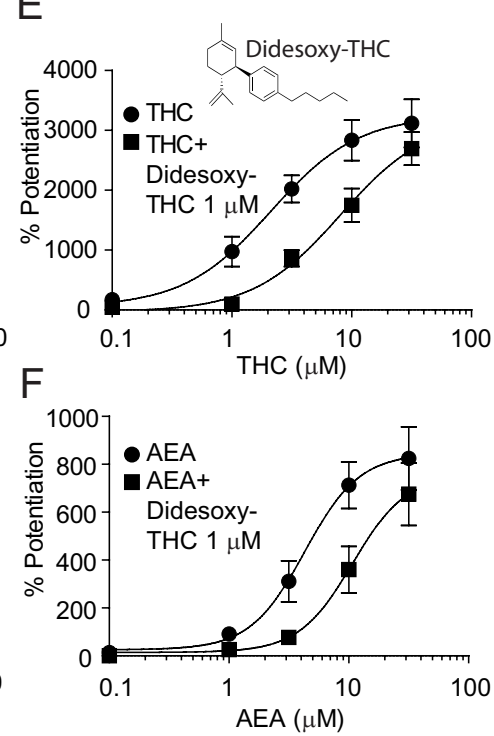

100

Figure 5. Desoxy-AEA shows reduced efficacy in potentiating $I_{G l y}$ and antagonizes both $A E A$ and THC-induced potentiation. $\boldsymbol{A}$, cells expressing the S296A mutant and wild-type $\alpha 1$ GlyRs. $n=5-8,{ }^{*} p<0.05,{ }^{* *} p<0.01,{ }^{* * *} p<0.001$, one-way ANOVA followed by Dunnett's post hoc test against wild-type. $\boldsymbol{B}$, The concentration-response curves for the AEA and modified AEA

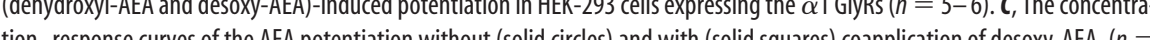
4-6). D, The concentration-response curves for THC potentiation without (solid circles) and with (solid squares) coapplication of desoxyof didesoxy-THC ( $n=5-8)$. $\boldsymbol{F}$, The concentration-response curves for AEA potentiation without (solid circles) and with (solid squares) coapplication of didesoxy-THC $(n=5-7)$. The error bars that are not visible are smaller than the size of symbols.

suggested that the G254 residue in TM2 of the $\alpha 1$ GlyR regulates the receptor's sensitivity to the endocannabinoid 2-arachidonoylglycerol when these compounds are coapplied with agonist (Yevenes and Zeilhofer, 2011a). In view of this, we examined the effect of the G254A mutation (Fig. $4 E$ ) on the maximal potentiating effect on $I_{\mathrm{Gly}}$ induced by AEA after 5 min sustained incubation with intermittent application of Gly. The G254A mutation did not significantly alter the sustained AEA incubation-induced potentiation of $I_{\text {Gly }}$ (Fig. $4 F, 695 \pm 77 \%$ vs $597 \pm 77 \%, p=0.40, n=5$, unpaired $t$ test).

\section{Chemical modification of AEA: critical role of hydroxyl/ oxygen groups of AEA}

Several phytocannabinoids such as THC and cannabidiol (CBD) can potentiate GlyRs (Hejazi et al., 2006; Yang et al., 2008; Ahrens et al., 2009). We next examined the influence of the S296A mutation on THC, CBD and HU210-induced potentiation of the $\alpha 1$ GlyR (Fig. 5A). The S296A mutation significantly reduced the potentiation of $I_{\mathrm{Gly}}$ induced by THC ( $1 \mu \mathrm{M}, p<0.001, n=8$, unpaired $t$ test $), \mathrm{CBD}(1 \mu \mathrm{M}, p<0.05, n=6$, unpaired $t$ test $)$ and HU210 ( $1 \mu \mathrm{M}, p<0.001, n=6$, unpaired $t$ test $)$. Removal of both 


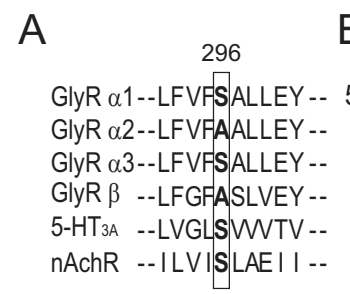

B AEA $0.1 \mu \mathrm{M}$ C
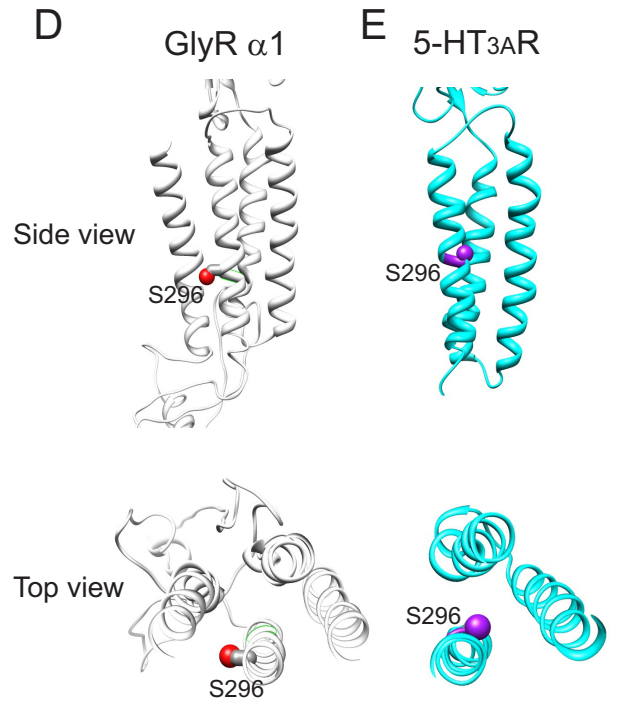

$\mathrm{F}$

\section{C}
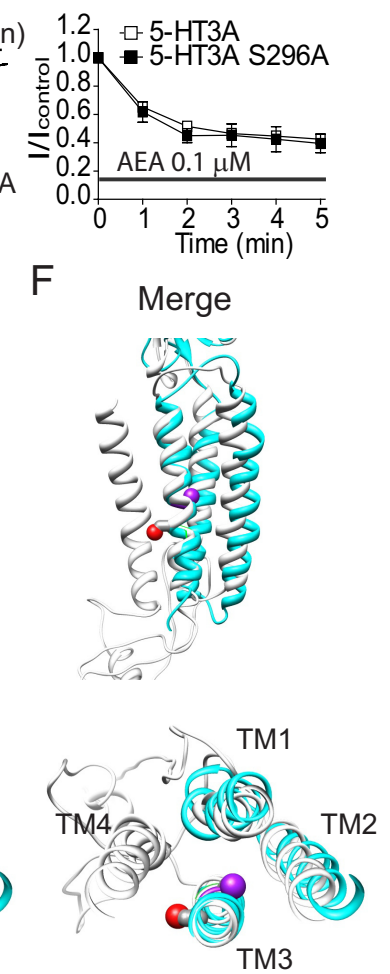

Figure 6. The $\mathrm{S} 296 \mathrm{~A}$ mutation does not alter AEA-induced inhibition of $5-\mathrm{HT}_{3 \mathrm{~A}}$ receptors. $\boldsymbol{A}$, Amino acid alignment of the TM3 region flanking $\mathbf{S 2 9 6}$ ( $\alpha 1 \mathrm{GlyR}$ ) or equivalent residues in other ligand-gated ion channels. $\boldsymbol{B}$, Representative current records for $I_{5-\mathrm{HT}}$ activated by a maximally efficacious concentration $(30 \mu \mathrm{M})$ of 5 -HT before, during and after a continuous incubation with 0.1 $\mu \mathrm{M}$ AEA in HEK-293 cells expressing human $5-\mathrm{HT}_{3 \mathrm{~A}} \mathrm{Rs}$. C, Time course of the average AEA inhibition of $I_{5-\mathrm{HT}}$ in HEK-293 cells expressing wild-type and $\mathrm{S} 296 \mathrm{~A}$ mutant $5-\mathrm{HT}_{3 \mathrm{~A}}$ receptors. Each point represents mean $\pm \mathrm{SE}$ of $5-7$ cells. $\boldsymbol{D}-\boldsymbol{F}$, Comparison of the S296 orientation between $\alpha 1 \mathrm{GlyR}$ (gray ribbons) and 5- $\mathrm{HT}_{3 \mathrm{~A}} \mathrm{R}$ (cyan ribbons) transmembrane domains. Side and top views of the transmembrane domains of $\mathrm{GlyR}(\boldsymbol{D}), 5-\mathrm{HT}_{3 \mathrm{~A}} \mathrm{R}(\boldsymbol{E})$, and their superimposition $(\boldsymbol{F})$. The sidechain oxygen atoms of $\mathrm{S} 296$ (shown as spheres) are colored in red for GlyR and in purple for $5-\mathrm{HT}_{3 \mathrm{~A}} \mathrm{R}$.

hydroxyl and oxygen groups from THC resulted in a new compound, didesoxy-THC, which substantially reduced THCinduced potentiation of the $\alpha 1$ GlyR (Xiong et al., 2011). While AEA and THC are structurally different, both compounds are potent agonists of $\mathrm{CB}_{1}$ receptors and likely bind to a similar molecular pocket of the receptor (Pertwee, 2008). We proposed that exogenous and endogenous cannabinoids interact with GlyRs via a similar molecular process. To test this hypothesis, we removed sequentially the hydroxyl or oxygen groups from AEA (Fig. 5B). The compounds with removal of hydroxyl (dehydroxyl-AEA) or oxygen group (desoxy-AEA) showed a reduced efficacy in potentiating $I_{\text {Gly }}$ in receptors containing the $\alpha 1$ subunit (Fig. 5B). The reduction in the efficacy of AEA potentiation was more obvious with removal of the oxygen group from AEA (desoxy-AEA). To determine whether THC and AEA may share common interacting sites on the GlyRs, we cross-examined the effect of desoxyAEA and didesoxy-THC on THC and AEA-induced potentiation of $I_{\mathrm{Gly}}$ in cells expressing the $\alpha 1$ subunits. Desoxy-AEA at $3 \mu \mathrm{M}$ inhibited the magnitude of AEA and THC-induced potentiation in an apparently competitive manner (Fig. $5 C, D$ ). Both concentration-response curves of AEA and THC-induced potentiation were shifted in parallel to the right in the presence of desoxy-AEA. Similarly, didesoxy-THC inhibited AEA and THC-induced potentiation in a competitive manner that was also observed in desoxy-AEA (Fig. $5 E, F$ ).

\section{S296 is not involved in AEA-induced inhibition of \\ $5-\mathrm{HT}_{3 \mathrm{~A}}$ receptors}

There is strong evidence that AEA can inhibit serotonin-gated ion channels (5$\left.\mathrm{HT}_{3 \mathrm{~A}} \mathrm{R}\right)$ through a direct interaction (Fan, 1995; Barann et al., 2002; Oz et al., 2002; Xiong et al., 2008). The $5-\mathrm{HT}_{3 \mathrm{~A}} \mathrm{R}$ and GlyR are both members of the Cys-loop LGIC superfamily and thus share a high level of amino acid sequence homology, especially within the transmembrane domains. For instance, the S296 residue is conserved between $5-\mathrm{HT}_{3 \mathrm{~A}} \mathrm{R}$ and GlyRs (Fig. 6A). In view of this, we explored the role of S296 in the sensitivity of 5- $\mathrm{HT}_{3 \mathrm{~A}} \mathrm{Rs}$ to AEA (Fig. 6A). Consistent with a previous observation (Xiong et al., 2008), incubation of AEA $(0.1 \mu \mathrm{M})$ for $5 \mathrm{~min}$ produced gradually developing inhibition of 5-HT $(30 \mu \mathrm{M})$-activated currents in HEK-293 cells expressing the WT 5- $\mathrm{HT}_{3 \mathrm{~A}}$ receptors (Fig. 6B). In these cells, the AEA-induced inhibition of $I_{5-\mathrm{HT}}$ reached a maximum after a continuous exposure to $0.1 \mu \mathrm{M}$ AEA for $5 \mathrm{~min}$. Even though AEA produced different types of modulation (inhibition vs potentiation) of $5-\mathrm{HT}_{3 \mathrm{~A}} \mathrm{Rs}$ and GlyRs, the time courses of AEA modulation of both receptors appeared similar. However, the S296A mutation of the $5-\mathrm{HT}_{3 \mathrm{~A}}$ receptors did not significantly alter the AEA-induced inhibition of 5-HT-activated current (Fig. 6C, $p=0.45, n=6-10$, Two-way ANOVA). This finding suggests that the S296A residue selectively regulates AEA modulation of GlyRs but not $5-\mathrm{HT}_{3 \mathrm{~A}}$ Rs. Although the S296 residue is conserved in the amino acid sequence of GlyR and 5- $\mathrm{HT}_{3 \mathrm{~A}} \mathrm{R}$, molecular modeling at the two dimensional level revealed that the orientation of S296 of GlyR differs from that of 5- $\mathrm{HT}_{3 \mathrm{~A}} \mathrm{R}$. For instance, S296 of GlyR is facing outside of the ion channel protein and lipid interface, a supposed docking site for AEA (Fig. 6 D). In contrast, S296 of $5-\mathrm{HT}_{3 \mathrm{~A}}$ receptor is hiding inside of the channel protein and away from lipid-protein interfaces (Fig. 6E). Both S296 residues do not overlap (Fig. 6F).

\section{Molecular docking of AEA and THC onto the $\alpha 1$ GlyR}

Molecular modeling of AEA/THC and the TM1-4 of the GlyR $\alpha 1$ subunit revealed that the hydroxyl groups (in red, Fig. $7 A, B$ ) of AEA and THC likely interact with the GlyR in a location between TM 3 and TM4 (Fig. 7C-F). The predicted interaction of AEA and THC with TM3 may occur via a hydrogen bond between the hydroxyl groups in AEA and the side chain of S296. AEA is well situated in the vicinity of TM3 -4 of the $\alpha 1$ subunit in the monomer and pentamer. The hydrogen bonding interaction between AEA/THC and the side chain of S296 can be clearly seen by the close contact of their hydroxyl groups. With the exception of this hydrogen bond, the remaining interactions between AEA/THC and GlyR are likely to be via van der Waals forces. 


\section{Discussion}

The data presented in this study suggest that both exogenous and endogenous cannabinoids potentiate GlyRs based on a common molecular process. Like THC, AEA-induced potentiation of $I_{\text {Gly }}$ developed gradually, and required sustained incubation. A similar finding was described in recent studies of the exogenous cannabinoid-induced potentiation of $I_{\mathrm{Gly}}$ in both spinal neurons and in cells expressing recombinant GlyRs (Xiong et al., 2011). This feature is also associated with cannabinoid modulation of a number of the Cys-loop LGICs. For instance, AEA inhibits $5-\mathrm{HT}_{3 \mathrm{~A}} \mathrm{Rs}$ and $\mathrm{nAChRs}$ in a timedependent manner, which required sustained incubation of AEA (Fan, 1995; Spivak et al., 2007). AEA differentially modulated different GlyR subunits in a manner similar to that of THC (Xiong et al., 2011). The amino acid residue serine at 296 was found to be critical for both AEA and THC-induced potentiating effect on $I_{\text {Gly }}$ in cells expressing the $\alpha 1$ and $\alpha 3$ subunits. Conversion of the equivalent residue, alanine, in the $\alpha 2$ subunit to serine rescued the sensitivity of the GlyRs to AEA and THC potentiation. The hydroxyl/oxygen groups appeared to be important functional groups for both AEA and THC in potentiating $I_{\mathrm{Gly}}$. Finally, deletion of these groups resulted in reduction in the efficacy of AEA and THC potentiation. Desoxy-AEA and didesoxy-THC competitively inhibited both AEA and THC-induced potentiation of GlyRs in a similar manner.

It is worth mentioning that different protocols for AEA application (sustained application vs simultaneous application with agonists) could cause several notable discrepancies between this study and previous reports. First, the maximal magnitude of AEA potentiation of the $\alpha 1$ GlyRs was estimated to be $80-100 \%$ by 1 $\mu \mathrm{M}$ AEA in previous studies when AEA was applied only simultaneously with Gly (Hejazi et al., 2006; Yang et al., 2008; Yevenes and Zeilhofer, 2011a). In the current study the maximal potentiation of the $\alpha 1$ GlyRs was nearly $700-800 \%$ when AEA was applied continuously for $5 \mathrm{~min}$ with intermittent supplication of Gly. Second, because of a substantial change in $E_{\max }$ of AEA potentiation and maximally efficacious concentration of AEA, the $\mathrm{EC}_{50}$ value of AEA potentiation of GlyRs increased from a range of 38-110 nM range described in previous studies to $4.2 \mu \mathrm{M} \mathrm{ob}-$ served in the current study. Third, AEA did not significantly alter $I_{\text {Gly }}$ in HEK-293 cells expressing the $\alpha 3$ GlyRs in a previous study (Yang et al., 2008; Yevenes and Zeilhofer, 2011a), whereas AEA significantly potentiated the $\alpha 3$ GlyRs as reported in this study, and it is likely that the larger effect of sustained AEA application explains this difference. Finally, the data presented in this study suggest that two distinct molecular processes may be involved in the potentiating effect on $I_{\mathrm{Gly}}$ induced by sustained AEA application with intermittent application of Gly and simultaneous AEA application with Gly. The S296A mutation appeared to selectively contribute to the mechanism underlying sustained cannabinoid- induced potentiation of the $\alpha 1$ and $\alpha 3$ subunits. The molecular determinants for simultaneous AEA and THC-induced potentiation remain elusive. There is no differential sensitivity of GlyR subunits to simultaneous AEA and THC-induced potentiation.

The S296 residue appeared critical for increased sensitivity of the $\alpha 1$ and $\alpha 3$ GlyRs to the AEA-induced potentiation of $I_{\text {Gly }}$ compared with the $\alpha 2$ subunit. Conversion of this amino acid residue to the corresponding alanine in the $\alpha 2$ subunit selectively altered the receptor's sensitivity to AEA potentiation without significantly changing the $\mathrm{EC}_{50}$ value for Gly or the expression level of receptor protein. The precise molecular mechanism by which S296 interacts with AEA remains to be determined. However, one prominent possibility is that S296 is involved in a hydrogen bonding interaction between AEA and GlyR protein. The most notable difference between the structures of alanine (A) and serine $(S)$ is that one of the methylic hydrogens in the serine side chain is substituted by a hydroxyl group. This allows serine to form a hydrogen bond with potential ligands/modulators. Consistent with this, molecular docking of the GlyR-AEA system suggests a high probability binding mode, perhaps via a possible hydrogen bonding interaction between AEA and the hydroxyl group of the side chains of S296. This hypothesis fits well with a recent study showing that the polarity of the amino acid residue at 296 or the equivalent position in both $\alpha 1$ and $\alpha 3$ GlyRs is correlated with the magnitude of THC-induced potentiation of $I_{\text {Gly }}$ (Xiong et al., 2011). Alternatively, the $S 296$ residue may play a role in sensing or stabilizing the AEA-induced conformational change that occurs at protein-lipid interface since S296 is thought 
to be located in the membrane-embedded portion of TM3 of GlyR proteins. This hypothesis is favored by the slow onset of AEA modulation of GlyRs as well as other LGICs, suggesting that AEA may have difficulty in molding itself to the lipid face of receptor transmembrane domains. Consistent with this hypothesis, it has been suggested that the lipid bilayer plays a central role in determining the location and orientation of AEA with respect to membrane targeted proteins (Di Marzo et al., 1998). It should be noted, however, that other residues that differ between the $\alpha 1 / \alpha 3$ and $\alpha 2$ subunits likely contribute to differential AEA potentiation of GlyRs. Both S296A and S307A mutations in the $\alpha 1$ and $\alpha 3$ subunits only partially inhibited the AEA potentiation.

While the expression level of the $\alpha 2$ subunit is significantly reduced after 1 week in cultured neurons, the $\alpha 1$ and $\alpha 3$ subunits are highly expressed in embryonic spinal cord neurons after a prolonged period ( 1 or 2 weeks) of in vitro growth (Aguayo et al., 2004). This expression pattern (high expression of the $\alpha 1$ and $\alpha 3$ subunits and low expression of the $\alpha 2$ subunits) in cultured spinal neurons fits well with what we found in this study. The sensitivity of GlyRs to AEA in native spinal neurons was similar to that of the $\alpha 1$ and $\alpha 3$ subunits expressed in HEK-293 cells. Subunit-specific modulation of GlyRs has been described for a number of allosteric modulators of GlyRs (Yevenes and Zeilhofer, 2011b). The $\alpha 1$ GlyRs are more sensitive to ethanolinduced potentiation compared with $\alpha 2$ and $\alpha 3$ GlyRs (Mascia et al., 1996; Perkins et al., 2008; Yevenes et al., 2010). Neurosteroids are also found to potentiate the GlyRs in a subunit-specific manner (Maksay et al., 2001). There is strong evidence that distinct molecular sites contribute to allosteric modulation of GlyRs by different substances (Lobo and Harris, 2005; Harris et al., 2008; Yevenes and Zeilhofer, 2011a). It is interesting to note that the S296 is not involved in AEA modulation of $5-\mathrm{HT}_{3 \mathrm{~A}} \mathrm{Rs}$ even though the S296 residue is conserved between the $\alpha 1$ GlyRs and $5-\mathrm{HT}_{3 \mathrm{~A}} \mathrm{Rs}$. Such a dramatic difference can be explained by the molecular modeling of the surrounding vicinity of S296 of the two receptors, which reveals different orientations of the S296 in its relationship with subunit interfaces and protein lipid interfaces.

AEA's binding affinity $\left(K_{\mathrm{i}}\right)$ for $\mathrm{CB}_{1}$ and $\mathrm{CB}_{2}$ receptors are 61-543 nM and 279-1940 nM (Pertwee, 2000). AEA at the concentration range $(1 \mu \mathrm{M})$ used in this study will likely activate $\mathrm{CB}_{1}$ and $\mathrm{CB}_{2}$ receptors in cultured spinal neurons. These receptors are unlikely to contribute to the effect of AEA on $I_{\mathrm{Gly}}$ in this study because selective antagonists of $\mathrm{CB}_{1}$ and $\mathrm{CB}_{2}$ receptors did not prevent the AEA potentiation of $I_{\mathrm{Gly}}$ in spinal neurons. Direct modulation of GlyRs by AEA through $\mathrm{CB}_{1}$-independent mechanism was also reported in a previous study (Lozovaya et al., 2005). It must be noted that AEA was found to inhibit $I_{\mathrm{Gly}}$ in the presence of $\mathrm{CB}_{1} / \mathrm{CB}_{2}$ receptor antagonists in hippocampal neurons (Lozovaya et al., 2005). One possible explanation for the different effects of AEA on $I_{\mathrm{Gly}}$ could be that different GlyR subunits and signal transduction pathways that exist in different neurons could also contribute to the apparently discrepant effects. Alternatively, the apparent discrepancy may be partially caused by differences in experimental design. For example, different concentrations of Gly were used in the two studies. We and others observed that the magnitude of AEA-induced potentiation of $I_{\mathrm{Gly}}$ depended on Gly concentrations (Hejazi et al., 2006; Yang et al., 2008). The maximal AEA potentiation was observed when the lowest concentrations of Gly were applied. The extent of the AEA-induced potentiation of $\alpha 1$ GlyRs could be reduced substantially when the concentrations of Gly were $>100 \mu \mathrm{M}$ as used in the Lozovaya et al. (2005) study. Thus other factors, such as receptor desensitization, must be considered when trying to explain the inhibition observed by Lozovaya et al. (2005).

The $\alpha 1$ GlyR is expressed mainly in the spinal motor neurons (Legendre, 2001; Lynch, 2004). Humans and rodents carrying certain single amino acid polymorphisms/mutations on the $\alpha 1$ GlyRs at postsynaptic sites have severe deficiencies in neuromotor activity (Shiang et al., 1993, 1995). The $\alpha 3$ GlyRs are abundantly expressed in the adult spinal cord dorsal horn where these receptors critically regulate inflammatory pain sensation (Harvey et al., 2004). Some reports showed that AEA-induced antinociception can occur through a $\mathrm{CB}_{1}$-independent pathway (Adams et al., 1998; Smith et al., 1998; Vivian et al., 1998; Zimmer et al., 1999; Di Marzo et al., 2000). Future studies are awaited for exploring in vivo consequences of AEA potentiation of GlyRs.

\section{References}

Adams IB, Compton DR, Martin BR (1998) Assessment of anandamide interaction with the cannabinoid brain receptor: SR 141716A antagonism studies in mice and autoradiographic analysis of receptor binding in rat brain. J Pharmacol Exp Ther 284:1209-1217.

Aguayo LG, van Zundert B, Tapia JC, Carrasco MA, Alvarez FJ (2004) Changes on the properties of glycine receptors during neuronal development. Brain Res Brain Res Rev 47:33-45.

Ahrens J, Demir R, Leuwer M, de la Roche J, Krampfl K, Foadi N, Karst M, Haeseler G (2009) The nonpsychotropic cannabinoid cannabidiol modulates and directly activates alpha-1 and alpha-1-Beta glycine receptor function. Pharmacology 83:217-222.

Arnold K, Bordoli L, Kopp J, Schwede T (2006) The SWISS-MODEL workspace: a web-based environment for protein structure homology modelling. Bioinformatics 22:195-201.

Barann M, Molderings G, Brüss M, Bönisch H, Urban BW, Göthert M (2002) Direct inhibition by cannabinoids of human 5-HT3A receptors: probable involvement of an allosteric modulatory site. Br J Pharmacol 137:589-596.

Brooks BR, Bruccoleri RE, Olafson BD, States DJ, Swaminathan S, Karplus M (1983) CHARMM: A program for macromolecular energy, minimization, and dynamics calculations. J Comput Chem 4:187.

Brooks BR, Brooks CL, Mackerell AD, Nilsson L, Petrella RJ, Roux B, Won Y, Archontis G, Bartels C, Boresch S, Caflisch A, Caves L, Cui Q, Dinner AR, Feig M, Fischer S, Gao J, Hodoscek M, Im W, Kuczera K, et al. (2009) CHARMM: The biomolecular simulation program. J Comput Chem 30:1545-1614.

Delaney AJ, Esmaeili A, Sedlak PL, Lynch JW, Sah P (2010) Differential expression of glycine receptor subunits in the rat basolateral and central amygdala. Neurosci Lett 469:237-242.

Di Marzo V, Melck D, Bisogno T, De Petrocellis L (1998) Endocannabinoids: endogenous cannabinoid receptor ligands with neuromodulatory action. Trends Neurosci 21:521-528.

Di Marzo V, Breivogel CS, Tao Q, Bridgen DT, Razdan RK, Zimmer AM, Zimmer A, Martin BR (2000) Levels, metabolism, and pharmacological activity of anandamide in $\mathrm{CB}(1)$ cannabinoid receptor knockout mice: evidence for non- $\mathrm{CB}(1)$, non- $\mathrm{CB}(2)$ receptor-mediated actions of anandamide in mouse brain. J Neurochem 75:2434-2444.

Fan P (1995) Cannabinoid agonists inhibit the activation of 5-HT3 receptors in rat nodose ganglion neurons. J Neurophysiol 73:907-910.

Foadi N, Leuwer M, Demir R, Dengler R, Buchholz V, de la Roche J, Karst M, Haeseler G, Ahrens J (2010) Lack of positive allosteric modulation of mutated alpha(1)S267I glycine receptors by cannabinoids. Naunyn Schmiedebergs Arch Pharmacol 381:477-482.

Guex N, Peitsch MC (1997) SWISS-MODEL and the Swiss-PdbViewer: an environment for comparative protein modeling. Electrophoresis 18:2714-2723.

Harris RA, Trudell JR, Mihic SJ (2008) Ethanol's molecular targets. Sci Signal 1:re7.

Harvey RJ, Depner UB, Wässle H, Ahmadi S, Heindl C, Reinold H, Smart TG, Harvey K, Schütz B, Abo-Salem OM, Zimmer A, Poisbeau P, Welzl H, Wolfer DP, Betz H, Zeilhofer HU, Müller U (2004) GlyR alpha3: an essential target for spinal PGE2-mediated inflammatory pain sensitization. Science 304:884-887.

Hejazi N, Zhou C, Oz M, Sun H, Ye JH, Zhang L (2006) Delta9- 
tetrahydrocannabinol and endogenous cannabinoid anandamide directly potentiate the function of glycine receptors. Mol Pharmacol 69:991-997.

Hu XQ, Sun H, Peoples RW, Hong R, Zhang L (2006) An interaction involving an arginine residue in the cytoplasmic domain of the 5-HT3A receptor contributes to receptor desensitization mechanism. J Biol Chem 281:21781-21788

Legendre P (2001) The glycinergic inhibitory synapse. Cell Mol Life Sci 58:760-793.

Lobo IA, Harris RA (2005) Sites of alcohol and volatile anesthetic action on glycine receptors. Int Rev Neurobiol 65:53-87.

Lozovaya N, Yatsenko N, Beketov A, Tsintsadze T, Burnashev N (2005) Glycine receptors in CNS neurons as a target for nonretrograde action of cannabinoids. J Neurosci 25:7499-7506.

Lynch JW (2004) Molecular structure and function of the glycine receptor chloride channel. Physiol Rev 84:1051-1095.

Lynch JW (2009) Native glycine receptor subtypes and their physiological roles. Neuropharmacology 56:303-309.

Maksay G, Laube B, Betz H (2001) Subunit-specific modulation of glycine receptors by neurosteroids. Neuropharmacology 41:369-376.

Mascia MP, Mihic SJ, Valenzuela CF, Schofield PR, Harris RA (1996) A single amino acid determines differences in ethanol actions on strychnine-sensitive glycine receptors. Mol Pharmacol 50:402-406.

$\mathrm{Oz}$ M, Zhang L, Morales M (2002) Endogenous cannabinoid, anandamide, acts as a noncompetitive inhibitor on 5-HT3 receptor-mediated responses in Xenopus oocytes. Synapse 46:150-156.

Oz M, Zhang L, Ravindran A, Morales M, Lupica CR (2004) Differential effects of endogenous and synthetic cannabinoids on alpha7-nicotinic acetylcholine receptor-mediated responses in Xenopus oocytes. J Pharmacol Exp Ther 310:1152-1160.

Perkins DI, Trudell JR, Crawford DK, Alkana RL, Davies DL (2008) Targets for ethanol action and antagonism in loop 2 of the extracellular domain of glycine receptors. J Neurochem 106:1337-1349.

Pertwee RG (2000) Cannabinoid receptor ligands: clinical and neuropharmacological considerations, relevant to future drug discovery and development. Expert Opin Investig Drugs 9:1553-1571.

Pertwee RG (2008) Ligands that target cannabinoid receptors in the brain: from THC to anandamide and beyond. Addict Biol 13:147-159.

Rácz I, Bilkei-Gorzo A, Markert A, Stamer F, Göthert M, Zimmer A (2008) Anandamide effects on 5-HT(3) receptors in vivo. Eur J Pharmacol 596:98-101.

Ross RA (2003) Anandamide and vanilloid TRPV1 receptors. Br J Pharmacol 140:790-801.

Schwede T, Kopp J, Guex N, Peitsch MC (2003) SWISS-MODEL: An automated protein homology-modeling server. Nucleic Acids Res 31:3381-3385.

Shiang R, Ryan SG, Zhu YZ, Hahn AF, O'Connell P, Wasmuth JJ (1993) Mutations in the alpha 1 subunit of the inhibitory glycine receptor cause the dominant neurologic disorder, hyperekplexia. Nat Genet 5:351-358.

Shiang R, Ryan SG, Zhu YZ, Fielder TJ, Allen RJ, Fryer A, Yamashita S,
O'Connell P, Wasmuth JJ (1995) Mutational analysis of familial and sporadic hyperekplexia. Ann Neurol 38:85-91.

Sigel E, Baur R, Rácz I, Marazzi J, Smart TG, Zimmer A, Gertsch J (2011) The major central endocannabinoid directly acts at $\mathrm{GABA}(\mathrm{A})$ receptors. Proc Natl Acad Sci U S A 108:18150-18155.

Smart D, Gunthorpe MJ, Jerman JC, Nasir S, Gray J, Muir AI, Chambers JK, Randall AD, Davis JB (2000) The endogenous lipid anandamide is a full agonist at the human vanilloid receptor (hVR1). Br J Pharmacol 129:227-230.

Smith FL, Fujimori K, Lowe J, Welch SP (1998) Characterization of delta9tetrahydrocannabinol and anandamide antinociception in nonarthritic and arthritic rats. Pharmacol Biochem Behav 60:183-191.

Spivak CE, Lupica CR, Oz M (2007) The endocannabinoid anandamide inhibits the function of alpha4beta2 nicotinic acetylcholine receptors. Mol Pharmacol 72:1024-1032.

Tapia JC, Aguayo LG (1998) Changes in the properties of developing glycine receptors in cultured mouse spinal neurons. Synapse 28:185-194.

Vivian JA, Kishioka S, Butelman ER, Broadbear J, Lee KO, Woods JH (1998) Analgesic, respiratory and heart rate effects of cannabinoid and opioid agonists in rhesus monkeys: antagonist effects of SR 141716A. J Pharmacol Exp Ther 286:697-703.

Wu X, Brooks BR (2003) Self-guided Langevin dynamics simulation method. Chem Phys Lett 381:512-518.

Wu X, Brooks BR (2011) Toward canonical ensemble distribution from self-guided Langevin dynamics simulation. J Chem Phys 134:134108.

Xiong W, Hosoi M, Koo BN, Zhang L (2008) Anandamide inhibition of 5-HT3A receptors varies with receptor density and desensitization. Mol Pharmacol 73:314-322.

Xiong W, Cheng K, Cui T, Godlewski G, Rice KC, Xu Y, Zhang L (2011) Cannabinoid potentiation of glycine receptors contributes to cannabisinduced analgesia. Nat Chem Biol 7:296-303.

Yang Z, Aubrey KR, Alroy I, Harvey RJ, Vandenberg RJ, Lynch JW (2008) Subunit-specific modulation of glycine receptors by cannabinoids and $N$-arachidonyl-glycine. Biochem Pharmacol 76:1014-1023.

Yevenes GE, Zeilhofer HU (2011a) Molecular sites for the positive allosteric modulation of glycine receptors by endocannabinoids. PLoS One 6:e23886.

Yevenes GE, Zeilhofer HU (2011b) Allosteric modulation of glycine receptors. Br J Pharmacol 164:224-236.

Yevenes GE, Moraga-Cid G, Avila A, Guzmán L, Figueroa M, Peoples RW, Aguayo LG (2010) Molecular requirements for ethanol differential allosteric modulation of glycine receptors based on selective Gbetagamma modulation. J Biol Chem 285:30203-30213.

Zhang L, Xiong W (2009) Modulation of the Cys-loop ligand-gated ion channels by fatty acid and cannabinoids. Vitam Horm 81:315-335.

Zimmer A, Zimmer AM, Hohmann AG, Herkenham M, Bonner TI (1999) Increased mortality, hypoactivity, and hypoalgesia in cannabinoid CB1 receptor knockout mice. Proc Natl Acad Sci U S A 96:5780-5785. 